\title{
From Where Did the Water Come That Filled the Earth's Oceans? A Widely Overlooked Redox Reaction
}

\author{
Friedemann T. Freund ${ }^{1,2,3}$, Minoru M. Freund ${ }^{1^{*}}$ \\ ${ }^{1}$ NASA Ames Research Center, Moffett Field, CA, USA \\ ${ }^{2}$ Department of Physics, San Jose State University, San Jose, CA, USA \\ ${ }^{3}$ Senior Scientist, SETI Institute, Mountain View, CA, USA \\ Email: friedemann.t.freund@nasa.gov
}

Received 15 February 2015; accepted 23 March 2015; published 26 March 2015

Copyright (C) 2015 by authors and Scientific Research Publishing Inc.

This work is licensed under the Creative Commons Attribution International License (CC BY). http://creativecommons.org/licenses/by/4.0/

(c) (i) Open Access

\begin{abstract}
Though two-thirds of Earth's surface is covered by oceans, measurements of hydroxyl concentrations in upper mantle minerals, specifically in olivine, reportedly provide surprisingly low values. This has been interpreted to mean that there is little dissolved $\mathrm{H}_{2} \mathrm{O}$ in the Earth's mantle. By inference, when Earth formed, there might not have been able enough water to fill the oceans through volcanic degassing. It has therefore been proposed that the missing water was delivered to Earth from space, through comets and other impacting bodies. However, the reported low hydroxyl concentrations in olivine and similar mineralsis probably based on a profound misunderstanding of a solid state reaction that converts hydroxyls into something more difficult to detect. There is indeed a redox reaction that converts, during cooling, solute hydroxyls in the matrix of minerals into peroxy plus $\mathrm{H}_{2}$. This widely overlooked redox conversion takes place under thermodynamic non-equilibrium conditions. Its significance is that any mineral and any rock available for collection at the Earth surface has gone through a process that causes hydroxyls, the telltale sign of dissolved $\mathrm{H}_{2} \mathrm{O}$, to change into peroxyplus $\mathrm{H}_{2}$. The $\mathrm{H}_{2}$ molecules are diffusively mobile and may leave even structurally dense mineral grains. The remaining peroxy thus become the memory of the "true" solute $\mathrm{H}_{2} \mathrm{O}$ content, besides a few residual hydroxyls. Though first described over 30 years ago, this redox conversion has been largely ignored. As a result it is unknown how much $\mathrm{H}_{2} \mathrm{O}$ is contained in the Earth's upper mantle but it is certainly much more than has been assumed until now on the basis of analysis of residual hydroxyls.
\end{abstract}

\section{Keywords}

Redox Conversion, Hydroxyls, Peroxy, Water, Earth's Upper Mantle

\footnotetext{
*Unfortunately, this author was deceased.

How to cite this paper: Freund, F.T. and Freund, M.M. (2015) From Where Did the Water Come That Filled the Earth's Oceans? A Widely Overlooked Redox Reaction. American Journal of Analytical Chemistry, 6, 342-349. 


\section{Introduction}

For decades astronomers and others have argued about how planet Earth got its water. Some believe the water to be as old as the Earth itself [1]-[4], others think that, because Earth's surface was once deeply molten, the planet could not retain its primordial water. Therefore, much of the water available now must have arrived later, presumably through collisions with comets [5]-[7]. The latter belief is based on observations that today's upper mantle appears to be relatively “dry”.

Laboratory measurements of olivine crystals and other minerals, brought up from the upper mantle by volcanic actions, suggest surprisingly low to very low "water" concentration in form of solute hydroxyls, $\mathrm{OH}^{-}$or $\mathrm{O}_{3} \mathrm{Si}-\mathrm{OH}$. Using mostly infrared (IR) spectroscopy as diagnostic tool, the minerals retrieved from upper mantle sources were indeed found to be generally low in hydroxyl, implying low $\mathrm{H}_{2} \mathrm{O}$ contents in the source region [8]-[10]. Since the water in the oceans must have degassed from the Earth's mantle, if upper mantle rocks were low in solute $\mathrm{H}_{2} \mathrm{O}$, there might not have been enough water to fill the oceans. This led to the idea that the only way to supply enough water to the Earth would have been by massive cometary impacts [5] [11] [12].

However, the argument is fallacious that low hydroxyl contents in upper mantle minerals collected at the Earth surface are a proof of low solute $\mathrm{H}_{2} \mathrm{O}$ contents in the source region. There is a way how minerals, which started out with fairly high concentrations of solute hydroxyls in the hot regions of the Earth's deeper crust and upper mantle, can end up at the surface of the Earth with much lower solute hydroxyl concentrations. The reason is a redox conversion that consumes solute hydroxyls in the matrix of minerals by converting them into peroxy plus molecular $\mathrm{H}_{2}$.

Here we present this still widely unknown solid state redox conversion, which is fundamentally important to understand the history and evolution of planet Earth.

\section{Thermodynamics of Solid Solutions and Supersaturated Solid Solutions}

To explain the redox conversion that changes hydroxyls into peroxy plus $\mathrm{H}_{2}$ we can neglect the chemical complexity of mantle minerals such as olivine, ideally $\left(\mathrm{Mg}, \mathrm{Fe}^{2+}\right)_{2} \mathrm{SiO}_{4}$. Instead we focus on the simplest binary oxide, $\mathrm{MgO}$ and ask: what happens when $\mathrm{MgO}$ incorporates small amounts of dissolved $\mathrm{H}_{2} \mathrm{O}$ in its crystal structure?

MgO single crystals are routinely grown from the melt in a carbon-arc-fusion furnace [13]. Though the procedure is typically done in air, the MgO melt produced by the carbon arc plasma is extremely reducing. Hence, the MgO crystals, which grow from the melt, should be highly reduced.

Paradoxically, by the time the carbon-arc-fusion grown MgO crystals have cooled to room temperature, they contain perox defects. However, peroxy defects are the hallmark of highly oxidizing conditions. This raises the question: Does the presence of peroxy defects in MgO crystals that have been grown under extremely reducing conditions violate the laws of thermodynamics? The answer is "no", because the peroxy defects are introduced under non-equilibrium conditions.

If peroxy defects in carbon arc fusion grown $\mathrm{MgO}$ crystals are the result of a non-equilibrium reaction in the solid state, what is this reaction and how might it shed light on processes that happen in Nature with minerals that have crystallized in the reducing environment of the Earth's upper mantle and were subsequently brought to the surface of the Earth?

Figure 1 shows the AO-rich side of a binary phase diagram for a high melting oxide material $\mathrm{AO}$ with $\mathrm{H}_{2} \mathrm{O}$ as gas/fluid phase component. AO can also be any silicate mineral. $T_{\text {melt }}$ indicates the melting temperature of pure AO, which is "nominally anhydrous", meaning that its structure does not have any regular lattice sites to accommodate solute $\mathrm{H}_{2} \mathrm{O}$. However, the presence of $\mathrm{H}_{2} \mathrm{O}$ in the AO melt causes $T_{\text {melt }}$ to decrease to $T_{\text {cryst }}$ and a finite concentration of the $\mathrm{H}_{2} \mathrm{O}$ component to become incorporated into the AO matrix in form of hydroxyls, $\mathrm{OH}^{-}$. The result is an $\mathrm{AO}-\mathrm{H}_{2} \mathrm{O}$ solid solution (ss).

Thermodynamics mandates that, with decreasing $\mathrm{T}$, the width of the $\mathrm{AO}-\mathrm{H}_{2} \mathrm{O}$ ss field must decrease. If it were possible to maintain thermodynamic equilibrium throughout cooling, the solute $\mathrm{OH}^{-}$would continuously segregate, until the width of the ss field shrinks to zero at $0 \mathrm{~K}$.

As long as thermodynamic equilibrium is maintained during cooling, the $\mathrm{MgO}-\mathrm{H}_{2} \mathrm{O}$ solid solution will adjust to the narrowing of the ss field. However, "exsolution" can only be achieved, if solute $\mathrm{OH}^{-} \mathrm{plus}^{\mathrm{Mg}^{2+}} \mathrm{va}^{-}$ cancies are able to diffuse from inside the grains to their surfaces or boundaries.

Segregation is a process that is diffusion-controlled. Thus, inextricably, the $\mathrm{MgO}-\mathrm{H}_{2} \mathrm{O}$ system will reach a 


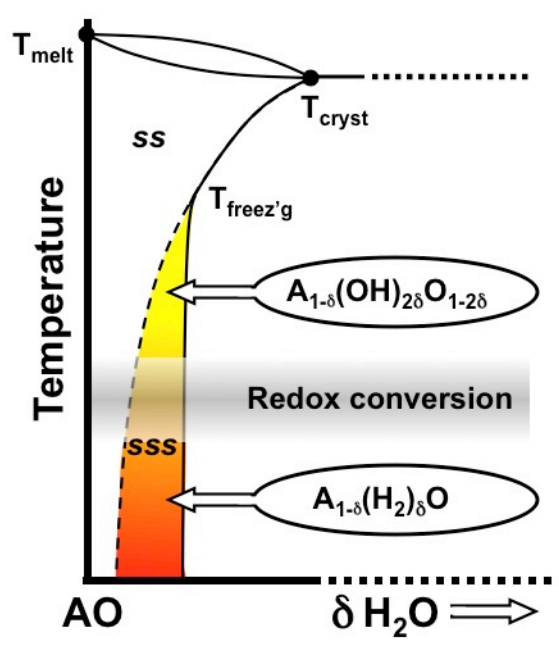

Figure 1. AO-side of binary $\mathrm{AO}-\mathrm{H}_{2} \mathrm{O}$ phase diagram showing the solid solution and supersaturated solid solution fields. AO can be an oxide or silicate mineral.

temperature $T_{\text {freez'g, }}$, below which segregation becomes too sluggish. Therefore, below $T_{\text {freez'g }}$, the solid solution (ss) leaves thermodynamic equilibrium and turns into a supersaturated solid solution (sss). Though $T_{\text {freez'g }}$ depends on the cooling rate, it typically falls into the $500^{\circ} \mathrm{C}-600^{\circ} \mathrm{C}$ range [14].

Since no changes in the overall composition of the sss system are supposed to take place.

Below $T_{\text {freez'g, }}$, we write the dissolution of $\delta \mathrm{H}_{2} \mathrm{O}$ in the $\mathrm{MgO}$ matrix simply as:

$$
\mathrm{MgO}+\delta \mathrm{H}_{2} \mathrm{O} \Leftrightarrow \mathrm{Mg}_{1-\delta}(\mathrm{OH})_{2 \delta} \mathrm{O}_{1-2 \delta}+\delta \mathrm{MgO}
$$

Equation (1) is mass-balanced. It states that $\delta$ are formed by introducing $2 \delta \mathrm{OH}^{-}$. In other words, in the MgO- $\mathrm{H}_{2} \mathrm{O}$ ss, $\delta \mathrm{Mg}^{+}$are substituted by $2 \delta \mathrm{H}^{+}$.

\section{Solute $\mathrm{OH}^{-}$in Solid Solution}

To more fully understand the complexity of what can happen in the sss field, we need to learn what kind of "impurity" $\mathrm{OH}^{-}$are part of the solid solution, more specifically

1) what types of $\mathrm{OH}^{-}$-bearing defects are formed;

2) where the $\mathrm{OH}^{-}$reside in the crystal matrix and;

3) what happens to them during further cooling through the sss field.

The substitutional mode given by Equation [1] predicts $\mathrm{OH}^{-}$pairs at $\mathrm{Mg}^{2+}$ vacancy sites as the main defect type, here labeled I. Using the Kröger-Vinck point defect designation ${ }^{1}$ defect I is written as $\left[\mathrm{OH}^{*} \mathrm{~V}_{\mathrm{Mg}}^{\prime \prime} \mathrm{HO}^{*}\right]^{x}$, where two $\mathrm{H}^{+}$compensate for the missing $\mathrm{Mg}^{2+}$. It will dissociate according to:

$$
\left[\mathrm{OH}^{*} \mathrm{~V}_{\mathrm{Mg}}^{\prime \prime} \mathrm{HO}^{\bullet}\right]^{x} \Leftrightarrow\left[\mathrm{OH}^{*} \mathrm{~V}_{\mathrm{Mg}}^{\prime \prime}\right]^{\prime}+\mathrm{OH}_{i}
$$

where defect II is a single $\mathrm{OH}^{-}$at an $\mathrm{Mg}^{2+}$ vacancy and defect III is an interstitial $\mathrm{OH}^{-}$with its proton at any $\mathrm{O}^{2-}$ in the $\mathrm{MgO}$ structure. The three defects are depicted in Figure 2(a) along with the expected relative intensities of their O-H stretching bands, $v_{\mathrm{OH}}$, according to Equation [2].

Figure 2(b) shows the measured IR spectrum with the assignment of the $v_{\mathrm{OH}}$ bands to the three types of $\mathrm{OH}^{-}$in the MgO matrix [16]. There is significant disagreement between the "expected" and the "observed" spectra. The $v_{\mathrm{OH}}$ band at $3560 \mathrm{~cm}^{-1}$, due to $\mathrm{OH}^{-}$pairs, defect I, does not show up with the highest intensity but with the lowest, leaving the $v_{\mathrm{OH}}$ band at $3700 \mathrm{~cm}^{-1}$, due to single $\mathrm{OH}^{-}$, to dominate the spectrum.

The most unusual feature, however, is the very weak band at $4150 \mathrm{~cm}^{-1}$. It is diagnostically distinct, unambi

${ }^{1} \mathrm{~V}$ stands for vacancy; subscripts identify the site (except for oxygen sites, where subscripts are omitted); superscript prime, dot, and $\mathrm{x}$ designate single negative, positive and neutral charges, respectively, double prime and double dot designate double negative and positive charges; subscript i means interstitial; square brackets outline the essential parts of any given point defect [Kröger, F. A. (1964), The Chemistry of Imperfect Crystals, North-Holland, Amsterdam.] [15]. 


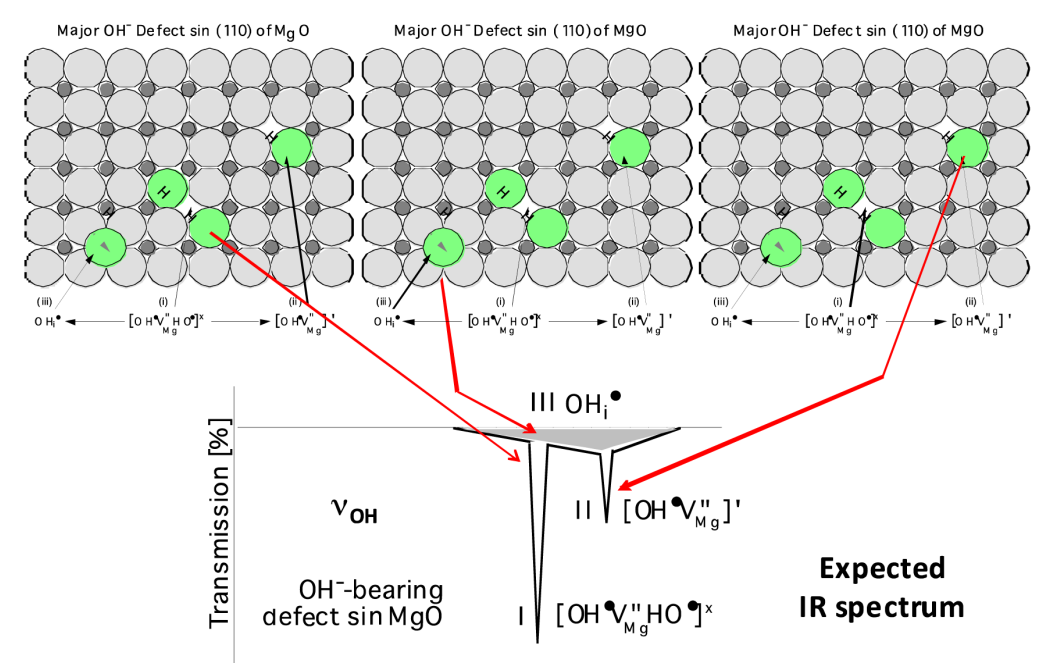

Higher wavenumbers $\Longleftrightarrow$ lower wavenumbers

(a)

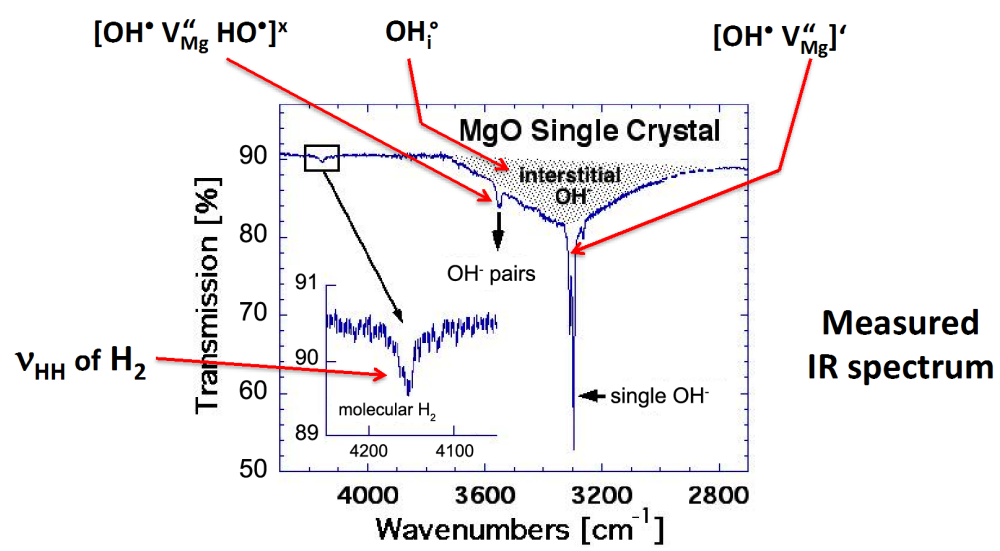

(b)

Figure 2. (a) $\mathrm{OH}^{-}$-bearing point defects derived from the dissolution of $\mathrm{H}_{2} \mathrm{O}$ in $\mathrm{MgO}$ and expected relative intensities of the $v_{\mathrm{OH}}$ bands due to $\mathrm{OH}^{-}$on the three dominant $\mathrm{OH}^{-}$-bearing defect sites. Of those three expected $v_{\mathrm{OH}}$ bands the one labeled I, due to $\mathrm{OH}^{-}$pairs at $\mathrm{Mg}^{2+}$ vacancies, should be most intense (after [Freund and Wengeler, 1982] [16]). The $v_{\mathrm{OH}}$ band arising from defect III, interstitial $\mathrm{OH}^{-}$, is broadened and intensified due to H-bonding [17]; (b) Measured IR spectrum: contrary to expectation the $v_{\mathrm{OH}}$ band due to $\mathrm{OH}^{-}$pairs at $\mathrm{Mg}^{2+}$ vacancy sites has the lowest intensity, allowing the $v_{\mathrm{OH}}$ band due to single $\mathrm{OH}^{-}$to dominate the spectrum. The band at $4150 \mathrm{~cm}^{-1}$ is due to $v_{\mathrm{HH}}$ indicating the presence of $\mathrm{H}_{2}$ molecules in the MgO matrix (after [Freund and Wengeler, 1982] [16]).

guously identifiable as due to lattice-bound $\mathrm{H}_{2}$ through the combination of the $\mathrm{H}$-H stretching mode $v_{\mathrm{HH}}$ with a phonon mode [18]. This assignment has been confirmed through the $v_{\mathrm{HD}}$ band in $\mathrm{MgO}$ crystals grown from a melt containing dissolved $\mathrm{D}_{2} \mathrm{O}$ [19].

\section{Redox Conversion of $\mathrm{OH}^{-}$Pairs to Peroxy plus $\mathrm{H}_{2}$}

First indication for molecular $\mathrm{H}_{2}$ was obtained nearly 40 years ago during a mass spectroscopic study of gases released from ultrahigh purity $\mathrm{OH}^{-}$-rich nano-sized $\mathrm{MgO}$ produced by the thermal decomposition of $\mathrm{Mg}(\mathrm{OH})_{2}$ [20]. Copious amounts of $\mathrm{H}_{2}$ were found to evolve from the $\mathrm{MgO}$ crystallites, followed by atomic $\mathrm{O}$ with a sharp on-set at $600^{\circ} \mathrm{C}$. The release of atomic $\mathrm{O}$ and sharp on-set at $600^{\circ} \mathrm{C}$ points to a on-set at disproportionation of peroxy:

$$
\mathrm{O}_{2}^{2-}=>\mathrm{O}^{2-}+\mathrm{O}
$$


Forming $\mathrm{H}_{2}$ from $\mathrm{OH}^{-}$requires a redox reaction. Since $\mathrm{Mg}$ is a main group metal with only one chemically accessible valence state, $2+$, in order to reduce hydroxyl protons to $\mathrm{H}_{2}$ something else must be oxidized. The only possibility is the hydroxyl oxygen changing its valence from $\mathrm{O}^{2-}$ to $\mathrm{O}^{-}$.

This turned out be true, involving the $\mathrm{OH}^{-}$-pairs of defect I in Figures 2(a) and Figure 2(b). In the process the oxygens of the two $\mathrm{OH}^{-}$transfer an electron to their respect protons [16], thereby oxidizing to the 1- valence state. The two $\mathrm{O}^{-}$coupleto form a peroxy anion, $\mathrm{O}_{2}^{2-}$. The two $\mathrm{H}$ atoms bind to form an $\mathrm{H}_{2}$ molecule at the $\mathrm{Mg}^{2+}$ vacancy site:

$$
\left[\mathrm{OH}^{\cdot} \mathrm{V}_{\mathrm{Mg}}^{\prime \prime} \mathrm{HO}^{\cdot}\right]^{x} \Leftrightarrow\left[\begin{array}{l}
\mathrm{O} \\
\mathrm{O} \cdot\left(\mathrm{H}_{2}\right)^{\prime \prime}{ }_{\mathrm{Mg}}
\end{array}\right]^{x}
$$

As a redox conversion this process requires nothing more than a local rearrangement of electrons and a slight shift of atomic positions. It can take place perfectly well in the sss state, under non-equilibrium conditions, in the region marked in gray in Figure 1, around or below $500^{\circ} \mathrm{C}$. As a result the concentration of $\mathrm{OH}^{-}$detectable via their $v_{\mathrm{OH}}$ bands must decrease significantly, suggesting a low solute $\mathrm{H}_{2} \mathrm{O}$ content.

Since $\mathrm{H}_{2}$ molecules are mobile, even in densely packed MgO, they can diffuse away from the $\mathrm{Mg}^{2+}$ vacancy site leaving behind an $\mathrm{Mg}^{2+}$ vacancy charge wise compensated by a peroxy anion, $\mathrm{O}_{2}^{2-}$ :

$$
\left[\mathrm{OH}^{\bullet} \mathrm{V}_{\mathrm{Mg}}^{\prime \prime} \mathrm{HO}^{\bullet}\right]^{x} \Leftrightarrow\left[\begin{array}{l}
\mathrm{O} \\
\mathrm{O} \cdot \bullet(\mathrm{V})^{\prime \prime} \\
\mathrm{Mg}
\end{array}\right]^{x}+\left(\mathrm{H}_{2}\right)_{i}^{x}
$$

Equation (4b) indicates that, when the $\mathrm{H}_{2}$ molecules may move away from the $\mathrm{Mg}^{2+}$ vacancy site, they become unavailable to convert back to $\mathrm{OH}^{-}$. The process continues by $\mathrm{H}_{2}$ molecules diffusing out:

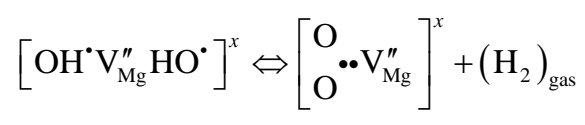

Equation (4c) marks the transition to irreversibility with $\mathrm{H}_{2}$ molecules having left the solid state. Thus, Equation (4c) describes the formation of a cation-deficient $\mathrm{MgO}, \mathrm{Mg}_{1-\delta} \mathrm{O}$. If $\delta \ll 1$, we may approximate its composition as $\mathrm{MgO}$ with excess-oxygen, $\mathrm{MgO}_{1+\delta}$.

Equations (4a/c) introduce peroxy, even though there was no need for the $\mathrm{MgO}-\mathrm{H}_{2} \mathrm{O}$ system to have ever experienced oxidizing conditions. The peroxy enters under non-equilibrium conditions via the above-mentioned redox conversion.

Other techniques in addition to mass spectrometry and IR spectroscopy have been employed to study the MgO- $\mathrm{H}_{2} \mathrm{O}$ sss system, specifically the electrical conductivity [21], thermal expansion [22], magnetic susceptibility [23], electron spin resonance [24], dielectric polarization [25], refractive index [26], and most recently muon spin relaxation [unpublished results] of MgO single crystals. These additional investigations have provided irrefutable evidence that, despite their provenance from the extremely highly reducing conditions of a carbon-arc-fusion melt [13] [27], melt-grown MgO crystals contain peroxy defects.

\section{Peroxy as the Memory of a Former Dissolved "Water" Content}

In plain chemical language the redox conversion of hydroxyl pairs can be written as:

$$
\mathrm{OH}^{-}+\mathrm{OH}^{-} \Leftrightarrow \mathrm{O}_{2}^{2-}+\mathrm{H}_{2}
$$

This is such a fundamental equation that it would be surprising, if the reaction were unique to the $\mathrm{MgO}-\mathrm{H}_{2} \mathrm{O}$ system. Indeed, this redox conversion appears to be universal, applicable as well as to silicates, where solute hydroxyls can be written as $\mathrm{O}_{3} \mathrm{X}-\mathrm{OH}$, with $\mathrm{X}=\mathrm{Si}^{4+}, \mathrm{Al}^{3+}$ etc. Hydroxyl pairs, $\mathrm{O}_{3} \mathrm{X}-\mathrm{OH} \mathrm{OH}-\mathrm{XO}_{3}$, whenever they exist, seem to be subject to the same redox conversion:

$$
\mathrm{O}_{3} \mathrm{Si}^{-} \mathrm{OH} \mathrm{HO}^{-} \mathrm{SiO}_{3} \Leftrightarrow \mathrm{O}_{3} \mathrm{Si}^{-} \mathrm{OO}^{-} \mathrm{SiO}_{3}+\mathrm{H}_{2}
$$

In fact there is evidence that every igneous rock that crystallized from a magma, every high-grade metamorphic rock originating from a high temperature, fluid-rich environment, and even every sedimentary rock that contains detrital grains of (mostly) quartz washed down from the mountains during weathering, will have $\mathrm{H}_{2}$ and peroxy defects [28]-[30]. Thus, the peroxy defects become a "memory", a universal "memory" of former solute 
$\mathrm{H}_{2} \mathrm{O}$ contents, along with residual hydroxyls that have not undergone this redox conversion.

The said argument also applies to upper mantle rocks, e.g. peridotites, and to olivine single crystals that have been brought up from mantle depth. As they cooled to Earth surface temperatures, they underwent the same redox conversion, changing their existing hydroxyls into peroxy plus $\mathrm{H}_{2}$.

While it is true that upper mantle-derived olivine come from highly reducing environment, olivine single crystals have also provided strong evidence for the presence of peroxy plus $\mathrm{H}_{2}$ [28] [31]. This implies that, while the olivine crystals resided in the upper mantle, they were significantly richer in hydroxyls, i.e. solute $\mathrm{H}_{2} \mathrm{O}$, than suggested by the low to very low residual hydroxyl contents, that has been provided by different types of chemical and spectroscopic of analyses of specimens collected at the Earth's surface. This implies that most of solute hydroxyls that there once part of the olivine- $\mathrm{H}_{2} \mathrm{O}$ solid solution at upper mantle depth have been lost in the temperature window marked in gray in Figure 1, due to their redox conversion to peroxy plus $\mathrm{H}_{2}$.

\section{Discussion}

The redox conversion of solute $\mathrm{H}_{2} \mathrm{O}$ to peroxy plus $\mathrm{H}_{2}$ has all the bearings of a universal redox reaction. It is expected to apply to all rocks residing in the Earth's rock column at temperatures below $\sim 500^{\circ} \mathrm{C}$. Regardless of the environment from where these rocks come, from a high temperature portion of the crust or from the upper mantle, whenever they crossed - as part of their geological history-the temperature window marked in gray in Figure 1, much of their original solute hydroxyl content would have converted to $\mathrm{H}_{2}$ plus peroxy according to Equations (5) and (6).

This leads us to the rather daring conclusion that only a small fraction of the "true" solute $\mathrm{H}_{2} \mathrm{O}$ content once contained, for instance, in the upper mantle will remain in form of residual $\mathrm{OH}^{-}$or $\mathrm{O}_{3} \mathrm{X}-\mathrm{OH}$, where $\mathrm{X}=\mathrm{Si}^{4+}$, $\mathrm{Al}^{3+}$, etc. This does not mean that those minerals suddenly became "dry" during transport to the Earth's surface but only that their solute $\mathrm{H}_{2} \mathrm{O}$ content is no longer expressed in form of hydroxyls. This conclusion, however, also implies that IR spectroscopy is ill-suited to assess the true solute $\mathrm{H}_{2} \mathrm{O}$ content. Hence, publications that rely on IR spectroscopy as analytical tool [9] [10] [32] [33] probably severely underestimated the "true" solute $\mathrm{H}_{2} \mathrm{O}$ content in Earth's upper mantle. Even techniques that probe $\mathrm{H}$ as an element such as SIMS and Ion Probes [34] [35] will not have been able to provide the "true" solute $\mathrm{H}_{2} \mathrm{O}$ contents, if some or most of the $\mathrm{H}_{2}$ molecules formed by the redox conversion had already out-diffused from the crystals under study.

The only way forward is to develop techniques that also probe peroxy concentrations. The reason is that, though the redox conversion of hydroxyl pairs into peroxy plus $\mathrm{H}_{2}$ has been described more than 30 years ago [16] and affirmed in the intervening years, the reality of peroxy in minerals and their potential role a memory of "true" $\mathrm{H}_{2} \mathrm{O}$ contents have not yet found sufficiently wide recognition within the community. An effort to develop the necessary analytical techniques to quantify peroxy contents is needed [25].

In summary, on the basis of available data, it can be stated with a high degree of confidence that the Earth's upper mantle has most likely contained in the past—and continues to contain today—plenty of "water" in the form of solute hydroxyls, probably enough to fill the worlds oceans. Cometary impacts, which attracted so much attentin over the years [5] [6], and are still widely discussed today, may not have been needed to "help out".

\section{Acknowledgements}

The results reported in this paper evolved over many years, starting with early studies supported in part by the Deutsche Forschungsgemeinschaft and continuing with support by the NASA Ames Research Center Director's Discretionary Fund and the NASA Earth Surface and Interior (ESI) program under grant \# NNX12AL71G.

\section{References}

[1] Fassett, C.I. and Minton, D.A. (2013) Impact Bombardment of the Terrestrial Planets and the Early History of the Solar System. Nature Geoscience, 6, 520-524. http://dx.doi.org/10.1038/ngeo1841

[2] Morbidelli, A., Chambers, J., Lunine, J.I., Petit1, J.M., Robert, F., Valsecchi, G.B. and Cyr, K.E. (2000) Source Regions and Timescales for the Delivery of Water to the Earth. Meteoritics and Planetary Science, 35, 1309-1320. http://dx.doi.org/10.1111/j.1945-5100.2000.tb01518.x

[3] Sarafian, A.R., Nielsen, S.G., Marschall, H.R., McCubbin, F.M. and Monteleone, B.D. (2014) Early Accretion of Water in the Inner Solar System from a Carbonaceous Chondrite-Like Source. Science, 346, 623-626.

http://dx.doi.org/10.1126/science.1256717 
[4] Shiga, D. (2010) Earth May Have Had Water from Day One. The New Scientist, 208, 12. http://dx.doi.org/10.1016/S0262-4079(10)62726-1

[5] Chyba, C.F. (1987) The Cometary Contribution to the Oceans of Primitive Earth. Nature, 330, 632-635. http://dx.doi.org/10.1038/330632a0

[6] Oberbeck, V.R. and Aggarwal, H. (1993) Comet Impacts and Chemical Evolution on the Bombarded Earth. Origins of Life and Evolution of the Biosphere, 21, 317-338. http://dx.doi.org/10.1007/BF01808305

[7] Robert, F. (2001) The Origin of Water on Earth. Science, 293, 1056-1058. http://dx.doi.org/10.1126/science.1064051

[8] Bell, D.R. and Rossman, G.R. (1992) Water in Earth’s Mantle: The Role of Nominally Anhydrous Minerals. Science, 255, 1391-1397. http://dx.doi.org/10.1126/science.255.5050.1391

[9] Bell, D.R., Rossman, G.R., Maldener, J., Endisch, D. and Rauch, F. (2003) Hydroxide in Olivine: A Quantitative Determination of the Absolute Amount and Calibration of the IR Spectrum. Journal of Geophysical Research (Solid Earth), 108, ECV 8-1. http://dx.doi.org/10.1029/2001JB000679

[10] Miller, G.H., Rossman, G.R. and Harlow, G.E. (1987) The Natural Occurrence of Hydroxide in Olivine. Physics and Chemistry of Minerals, 14, 461-472. http://dx.doi.org/10.1007/BF00628824

[11] Bolfan-Casanova, N. (2005) Water in the Earth’s Mantle. Mineralogical Magazine, 69, 229-257. http://dx.doi.org/10.1180/0026461056930248

[12] Owen, C.T. (1999) What Do We Know about the Origin of the Earth’s Oceans? Scientific American, 21 October 1999.

[13] Abraham, M.M., Butler, C.T. and Chen, Y. (1971) Growth of High-Purity and Doped Alkaline Earth Oxides, Part I: Magnesium Oxide and Calcium Oxide. The Journal of Chemical Physics, 55, 3752-3756. http://dx.doi.org/10.1063/1.1676658

[14] Nesse, W.D. (2000) Introduction to Mineralogy. Oxford University Press, New York.

[15] Kröger, F.A. (1964) The Chemistry of Imperfect Crystals. North-Holland, Amsterdam.

[16] Freund, F. and Wengeler, H. (1982) The Infrared Spectrum of OH-Compensated Defect Sites in C-Doped MgO and $\mathrm{CaO}$ Single Crystals. Journal of Physics and Chemistry of Solids, 43, 129-145. http://dx.doi.org/10.1016/0022-3697(82)90131-7

[17] Steiner, T. (2002) The Hydrogen Bond in the Solid State. Angewandte Chemie International Edition, 41, 48-76. http://dx.doi.org/10.1002/1521-3773(20020104)41:1<48::AID-ANIE48>3.0.CO;2-U

[18] Kriegler, R.J. and Welch, H.L. (1968) Induced Infrared Fundamental Band of Hydrogen Dissolved in Solid Argon. Canadian Journal of Physics, 46, 1181-1189. http://dx.doi.org/10.1139/p68-151

[19] Freund, F., Wengeler, H. and Martens, R. (1982) A Hydrogen-Deuterium Fractionation Mechanism in Magnesium Oxide. Geochimica et Cosmochimica Acta, 46, 1821-1829. http://dx.doi.org/10.1016/0016-7037(82)90121-1

[20] Martens, R., Gentsch, H. and Freund, F. (1976) Hydrogen Release during the Thermal Decomposition of Magnesium Hydroxide to Magnesium Oxide. Journal of Catalysis, 44, 366-372. http://dx.doi.org/10.1016/0021-9517(76)90413-9

[21] Kathrein, H. and Freund, F. (1983) Electrical Conductivity of Magnesium Oxide Single Crystal below 1200 K. Journal of Physics and Chemistry of Solids, 44, 177-186. http://dx.doi.org/10.1016/0022-3697(83)90052-5

[22] Wengeler, H. and Freund, F. (1980) Atomic Carbon in Magnesium Oxide, Part III: Anomalous Thermal Expansion Behavior. Materials Research Bulletin, 15, 1241-1245. http://dx.doi.org/10.1016/0025-5408(80)90026-4

[23] Batllo, F., LeRoy, R.C., Parvin, K., Freund, F. and Freund, M.M. (1991) Positive Hole Centers in Magnesium OxideCorrelation between Magnetic Susceptibility, Dielectric Anomalies and Electric Conductivity. Journal of Applied Physics, 69, 6031-6033. http://dx.doi.org/10.1063/1.347807

[24] Kathrein, H., Freund, F. and Nagy, J. (1984) $\mathrm{O}^{-}$-Ions and Their Relation to Traces of $\mathrm{H}_{2} \mathrm{O}$ and $\mathrm{CO}_{2}$ in $\mathrm{Magnesium}$ Oxide: An EPR Study. Journal of Physics and Chemistry of Solids, 45, 1155-1163. http://dx.doi.org/10.1016/0022-3697(84)90011-8

[25] Freund, F., Freund, M.M. and Batllo, F. (1993) Critical Review of Electrical Conductivity Measurements and Charge Distribution Analysis of MgO. Journal of Geophysical Research, 98, 22209-22229. http://dx.doi.org/10.1029/93JB01327

[26] Freund, F., Whang, E.-J., Batllo, F., Desgranges, L., Desgranges, C. and Freund, M.M. (1994) Positive Hole-Type Charge Carriers in Oxide Materials. In: Levinson, L.M., Ed., Grain Boundaries and Interfacial Phenomena in Electronic Ceramics, American Ceramic Society, Cincinnati, 263-278.

[27] Butler, C.T., Sturm, B.J. and Quincy, R.B. (1971) Arc Fusion Growth and Characterization of High-Purity Magnesium Oxide Single Crystals. Journal of Crystal Growth, 8, 197-204. http://dx.doi.org/10.1016/0022-0248(71)90142-4

[28] Freund, F., Dickinson, J.T. and Cash, M. (2002) Hydrogen in Rocks: An Energy Source for Deep Microbial Communities. Astrobiology, 2, 83-92. http://dx.doi.org/10.1089/153110702753621367 
[29] Freund, F. (2011) Pre-Earthquake Signals: Underlying Physical Processes. Journal of Asian Earth Sciences, 41, 383400. http://dx.doi.org/10.1016/j.jseaes.2010.03.009

[30] Freund, F.T. (2013) Earthquake Forewarning-A Multidisciplinary Challenge from the Ground up to Space. Acta Geophysica, 61, 775-807. http://dx.doi.org/10.2478/s11600-013-0130-4

[31] Freund, F.T. (2003) On the Electrical Conductivity Structure of the Stable Continental Crust. Journal of Geodynamics, 35, 353-388. http://dx.doi.org/10.1016/S0264-3707(02)00154-0

[32] Aines, R.D. and Rossman, G.R. (1984) Water in Minerals-A Peak in the Infrared? Journal of Geophysical Research, 89, 4059-4071. http://dx.doi.org/10.1029/JB089iB06p04059

[33] Rossman, G.R. (1990) Hydrogen in “Anhydrous” Minerals. Nuclear Instruments and Methods in Physics Research, B45, 41-44. http://dx.doi.org/10.1016/0168-583X(90)90780-X

[34] Koga, K., Hari, E., Hirschmann, M. and Bell, D. (2003) Hydrogen Concentration Analyses Using SIMS and FTIR: Comparison and Calibration for Nominally Anhydrous Minerals. Geochemistry, Geophysics, Geosystems, 4, 1-20. http://dx.doi.org/10.1029/2002GC000378

[35] Stephant, A., Remusat, L., Thomena, A. and Robert, F. (2014) Reduction of OH Contamination in Quantification of Water Contents Using NanoSIMS Imaging. Chemical Geology, 380, 20-26.

http://dx.doi.org/10.1016/j.chemgeo.2014.04.018 